\title{
Control of Synaptic Depression by Glutamate Transporters
}

\author{
Rostislav Tureček and Laurence O. Trussell \\ Oregon Hearing Research Center and Vollum Institute, Oregon Health Sciences University, Portland, Oregon 97201
}

The role of glutamate transporters in the regulation of synaptic depression was examined in the avian nucleus magnocellularis. Repetitive stimulation of presynaptic auditory nerve fibers resulted in acute depression of EPSCs. Pharmacological blockade of glutamate transport in glial cells enhanced residual glutamate in the synaptic cleft and markedly increased the extent of depression at stimulus frequencies above $20 \mathrm{~Hz}$ via a postsynaptic mechanism. Glutamate pyruvate transaminase, a glutamate scavenger, accelerated the decay of the EPSC and reduced synaptic depression, indicating that transporters are not completely effective in rapid removal of glutamate. Regulation of residual transmitter by glia may thus serve to control synaptic strength in a frequency-dependent manner.

Key words: AMPA; auditory; plasticity; depression; synapse; cochlear nucleus
The removal of glutamate from the synaptic cleft is accomplished through passive diff usion of transmitter and its subsequent uptake by glutamate transporters located in glial cells and neurons (Gegelashvili and Schousboe, 1998). Such uptake ultimately recycles transmitter and prevents excitotoxic damage (Rothstein et al., 1996; Tanaka et al., 1997). What immediate effect the activity of transporters has on low-frequency EPSCs depends on the density, location, and affinity of the transporters, as well as factors related to the sites and amount of transmitter release (Trussell, 1998). These factors are clearly not constant at all synapses in the CNS, because block of uptake by selective antagonists has widely varying effects in different brain regions and preparations (Trussell, 1998). Moreover, the role of transporters during activation of the synapse at physiological firing rates is not well understood. One might expect, for example, that repetitive stimulation would, in the absence of transport, result in rapid accumulation of transmitter. Such build-up of glutamate could then inhibit synaptic function, either presynaptically through metabotropic glutamate receptors (Maki et al., 1994; Scanziani et al., 1997) or postsynaptically by desensitization of glutamate receptors (Otis et al., 1996a).

In neurons of the cochlear nucleus magnocellularis (nMag) of the chick, end-bulb synaptic terminations of the auditory nerve produce large EPSCs mediated by AMPA receptors (Z hang and Trussell, 1994a,b). Repetitive activation of these synapses results in strong synaptic depression because of both presynaptic and postsynaptic factors, the latter representing receptor desensitization (Trussell et al., 1993; Otis et al., 1996a). In a previous study of this preparation, block of glutamate transport at room temperature using selective antagonists was observed to have little effect on the time course of the EPSC, only prolonging a small slow phase of the EPSC (Otis et al., 1996b). This slow component of the EPSC was proposed to reflect the slow removal of residual

\footnotetext{
Received Oct. 28, 1999; revised Dec. 9, 1999; accepted Dec. 22, 1999.

This work was supported by National Institutes of Health Grant NS28901 (L.O.T.) and Grant TW05406-01 from the Fogarty International Center, National Institutes of Health (R.T.). We thank Craig Jahr and Tom Otis for helpful conversations and a reading of this manuscript.

Correspondence should be addressed to L. Trussell, L-335A, Oregon Hearing Research Center, Oregon Health Sciences University, 3181 SW Sam Jackson Park Road, Portland, OR 97201. E-mail: trussell@ohsu.edu.

Copyright (C) 2000 Society for Neuroscience $0270-6474 / 00 / 202054-10 \$ 15.00 / 0$
}

transmitter from the synaptic cleft. Here, we report the effects of increasing or decreasing the clearance rate of glutamate on synaptic depression. We found that transporters acted primarily to minimize, but could not eliminate, the short-term accumulation of glutamate and subsequent desensitization of AMPA receptors and that enhancement of glutamate removal increased synaptic strength.

Parts of this work have been published previously in abstract form (Tureček and Trussell, 1998).

\section{MATERIALS AND METHODS}

These experiments were performed at the Department of Physiology, University of Wisconsin-Madison; all experimental procedures followed the guidelines of the Animal Care and Use Committee of that institution. Brainstem slices $(300 \mu \mathrm{m})$ prepared from embryonic day 18 (E18) to E19 chick embryos (Zhang and Trussell, 1994b; Otis et al., 1996b) were stored in and, during recordings, perfused at $3 \mathrm{ml} / \mathrm{min}$ with an oxygenated extracellular solution $\left(35-37^{\circ} \mathrm{C}\right)$ composed of (in mM): $140 \mathrm{NaCl}, 20$ glucose, $5 \mathrm{KCl}, 1 \mathrm{MgCl}_{2}, 3 \mathrm{CaCl}_{2}$, and $10 \mathrm{HEPES}$ (315 mOsm) at $\mathrm{pH} 7.3$ with $\mathrm{NaOH}$. Slices were bathed in antagonists of NMDA, GABA , and

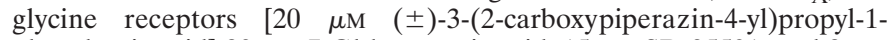
phosphonic acid] $20 \mu \mathrm{M}$ 7-Cl-kynurenic acid, $15 \mu \mathrm{M}$ SR-95531, and $2 \mu \mathrm{M}$ strychnine to isolate AMPA receptor-mediated EPSCs. Recording pipettes for whole-cell recording of EPSCs contained (in $\mathrm{mM}$ ): 125 $\mathrm{CsMeSO}_{3}, 15 \mathrm{CsCl}, 5 \mathrm{EGTA}, 1 \mathrm{MgCl}_{2}$, and $10 \mathrm{HEPES}$ (290 mOsm) at $\mathrm{pH} 7.2$ with $\mathrm{CsOH}$. For recordings of orthodromic action potential activity, pipettes contained (in $\mathrm{mm}$ ): $107.5 \mathrm{~K}$-gluconate, $32.5 \mathrm{KCl}, 5$ EGTA, $1 \mathrm{MgCl}_{2}$ and $10 \mathrm{HEPES}(285 \mathrm{mOsm})$ at $\mathrm{pH} 7.3$ with $\mathrm{KOH}$. For recordings of transporter-evoked currents, the bath solution given above was supplemented with $50 \mu \mathrm{M}$ 6,7-dinitroquinoxaline-2,3-dione, $40 \mu \mathrm{M}$ GYKI-52466, $10 \mathrm{~mm}$ TEA, $1 \mathrm{~mm}$ 4-aminopyridine, and $1 \mu \mathrm{M}$ tetrodotoxin, and the pipette fill contained (in $\mathrm{mm}$ ): $110 \mathrm{KNO}_{3}, 30 \mathrm{KCl}, 1$ $\mathrm{MgCl}_{2}, 5$ EGTA, and $10 \mathrm{HEPES}(280 \mathrm{mOsm})$ at $\mathrm{pH} 7.3$ with $\mathrm{KOH}$. Voltages are corrected for junction potentials of -11.7 (K-gluconatebased filling solution), $-6.5\left(\mathrm{KNO}_{3}\right)$ and $-8.8\left(\mathrm{CsMeSO}_{3}\right) \mathrm{mV}$. Glutamate pyruvate transaminase (GPT) was applied by pressure ejection (0.12-0.42 psi, diameter of mouth of an application pipette was $30 \mu \mathrm{m}$; distance from cell, 40-50 $\mu \mathrm{m}$ ) (Picospritzer II; General Valve, Fairfield, $\mathrm{NJ}$ ) or by bath perfusion. Concentration of GPT was 5-60 U/ml, as indicated, and enzyme applied in the presence of 2-20 mm pyruvic acid. Osmolality of all extracellular solutions was checked and adjusted with water to $\sim 320 \mathrm{mOsm}$. Viscosity of extracellular solutions was not measurably changed by addition of GPT $(60 \mathrm{U} / \mathrm{ml})$ when assayed using a falling-ball viscometer (Gilmont, Barrington, IL). In some cases, pyridoxal 5-phosphate $(10 \mu \mathrm{M})$ was added to perfusion solution.

Neurons were viewed using a Zeiss (Oberkochen, Germany) Axioskop FS with differential interference contrast optics and a $60 \times$ water immer- 

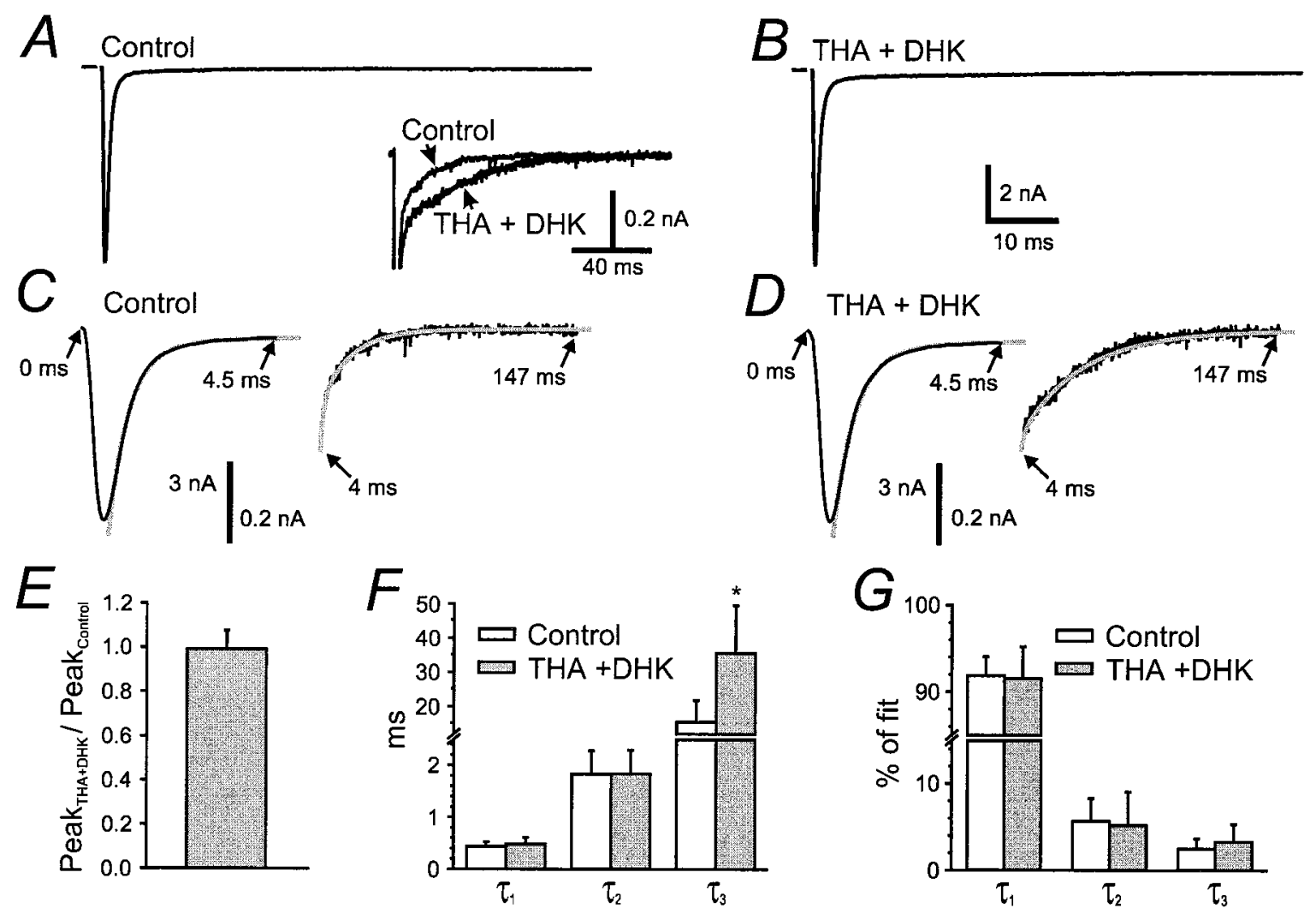

Figure 1. Action of transporter blockers on time course of single EPSCs. $A, B$, Control EPSC and EPSC in THA+DHK (300 $\mu \mathrm{M}$ each) in one cell. Holding potential of $-30 \mathrm{mV}$. Inset, overlay of traces in $A$ and $B$, emphasizing late phase of decay. $C, D$, EPSCs in control and THA+DHK, as indicated, with three-exponential curves ( gray) superimposed on the decay phase. Insets emphasize the fit of the curve to the late phases of decay. Arrows indicate times after onset of the response. $E$, Average change in peak of low-frequency EPSCs induced by THA+DHK $(n=11)$. $F$, Values of the time constants in control and uptake blockers for three-exponential fits to decay of low-frequency EPSCs $(n=12)$. $G$, Relative magnitudes of each component in the fitted curves.

sion objective. Borosilicate glass electrodes for whole-cell recording had resistances of 3-4 M $\Omega$, and series resistances during recordings were $<7$ $\mathrm{M} \Omega$ and were compensated electronically by $>90 \%$. Neurons were voltage clamped to $-30 \mathrm{mV}$ and glial cells to $-70 \mathrm{mV}$, unless otherwise indicated. For recordings from glial cells, the electrodes were 6-7 M $\Omega$, with series resistances of 13-25 M $\Omega$, compensated by $80 \%$. EPSCs were elicited (100 $\mu \mathrm{sec}, 40-50 \mathrm{~V}$ of stimuli) with an extracellular glass pipette. Zhang and Trussell (1994a) discussed evidence that this method of stimulation activates a single axonal input in nMag. EPSCs and EPSPs were recorded with an Axopatch 200B (Axon Instruments, Foster City, $\mathrm{CA}$ ), filtered at $5 \mathrm{kHz}$, and were digitized at $20 \mathrm{kHz}$ and analyzed using pClamp software (Axon Instruments). Transporter currents were filtered at $1 \mathrm{kHz}$ and sampled at $2 \mathrm{kHz}$. Reagents were obtained from Sigma (St. Louis, MO), Tocris-Cookson (St. Louis, MO), Research Biochemicals (Natick, MA), and ICN Biochemicals (Costa Mesa, CA). Cyclothiazide was a gift from Lilly Corp. Neurons were identified by their typical morphology (spherical round cells of diameter $\sim 20 \mu \mathrm{m}$, only one apparent process), their ability to generate an EPSC and an action potential, and their typical current responses evoked by voltage steps (Zhang and Trussell, 1994a,b). Glia were identified as small cells $(6-8 \mu \mathrm{m}$, flat oval or irregular shape, several tiny processes) with no spontaneous EPSCs, incapable of action potential generation, and a characteristic profile of outward current responses evoked by depolarizing voltage pulses.

Exponential current decays were fitted using the Chebyshev algorithm in pClamp 6.0. In initial experiments, the fitting results were checked by refitting the data using the slower Simplex algorithm (fractional error criterion $10^{-5}$ ), which showed excellent agreement. In measuring the amplitude of EPSCs in a train, the peak of each EPSC was determined relative to a baseline established by fitting a double exponential to the decay of the previous EPSC in the train. Means are reported $\pm 1 \mathrm{SD}$. Populations were compared using paired and unpaired $t$ tests.

\section{RESULTS}

\section{Role of transporters during low-frequency synaptic activity}

Glutamate transport was inhibited by bath application of extracellular solution containing $300 \mu \mathrm{M}$ D,L-threo- $\beta$-hydroxyaspartic acid (THA) and $300 \mu \mathrm{M}$ dihydrokainic acid (DHK), termed THA+DHK. In a later section, we show that this mixture effectively inhibits ionic currents generated by glutamate transporters. THA was observed to activate weakly NMDA receptors in neurons (see Fig. $8 F$ ), whereas DHK did not activate ionotropic glutamate receptors (Tong and Jahr, 1994) or modify their responses to exogenously applied glutamate (data not shown). Thus, in the presence of NMDA receptor antagonists, $\mathrm{THA}+\mathrm{DHK}$ was adequate for examining the effect of transporters on EPSCs.

Figure 1 shows the action of THA+DHK on EPSCs evoked by stimulation of a single presynaptic axon at $0.03 \mathrm{~Hz}$. No effect was seen on the amplitude of the EPSCs (Fig. 1A,B,E), even after 20 min exposure to the antagonists. Although the EPSCs decayed almost completely within a few milliseconds, there was a small, slow "tail" after the EPSC; this current tail was prolonged by THA+DHK, as shown in Figure $1 A-D$. To quantify this effect, the decay phase of EPSCs was fitted with a sum of three exponentials (Fig. 1C,D) (Otis et al., 1996a). Figure 1, $F$ and $G$, shows that only the time constant of the third, slowest exponential was slowed by the uptake blockers, although the relative weights of all 


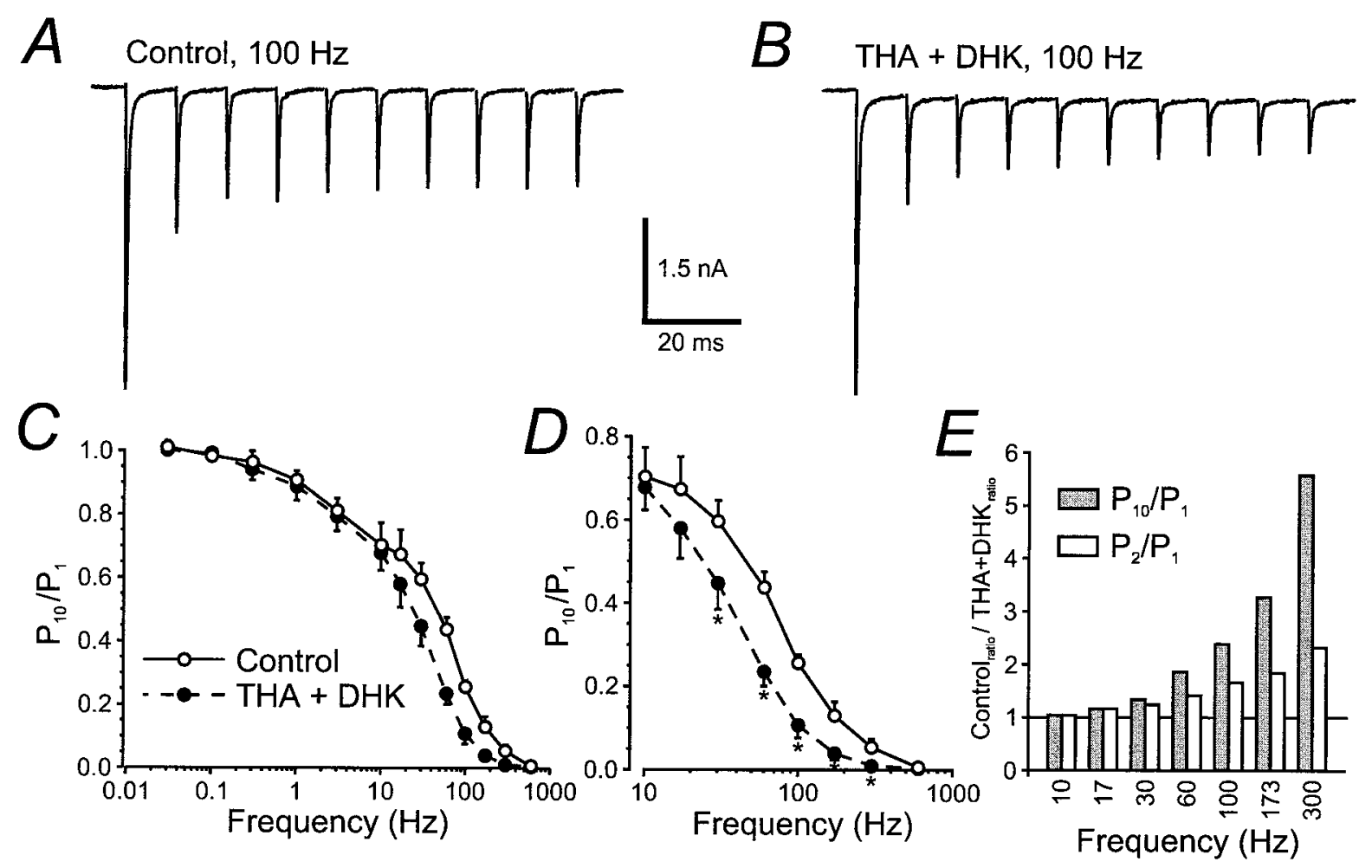

Figure 2. Effect of transport blockers on frequency-dependent depression. $A, B$, Train of $10 \mathrm{EPSCs}$ elicited at $100 \mathrm{~Hz}$ before and during application of THA +DHK. Data from one cell. $C$, Ratio of the average amplitude of 10th and 1st EPSCs in a train, elicited at different frequencies. Control, $n=10$; THA, $n=9$. $D$, The region of data in $C$ in which blockers altered depression. Asterisk indicates significant difference from control solutions $(p<0.01)$. $E$, Ratios of the relative amplitude (normalized to first EPSC) of the 10th and 2nd EPSCs in a train in control and blocker solution at different stimulus frequencies (solid bars). At $300 \mathrm{~Hz}$, EPSCs were nearly six times larger in control solutions. Open bars show ratio of second EPSCs in control and blockers, indicating that a greater effect of blockers is seen with longer trains.

three components remained the same as in control solutions. As discussed previously (Otis and Trussell, 1996; Otis et al., 1996b), the faster two components are related to the kinetics of AMPA receptors and the asynchrony of vesicle release, whereas the slow phase reflects slow clearance of low levels of glutamate. The selective prolongation of the slow phase is consistent with the hypothesis that transporters act only fast enough to remove glutamate over a period of tens of milliseconds, although diffusion is rapid enough to clear the majority of transmitter from the cleft within milliseconds.

\section{Repetitive EPSCs during transport block}

At higher synaptic stimulus rates, block of transport resulted in larger changes in EPSC amplitude. Figure 2, $A$ and $B$, shows a response to a $100 \mathrm{~Hz}$ train of 10 synaptic stimuli in control solution and in THA+DHK. Although the size of the first EPSC in the train was unchanged, subsequent EPSCs were smaller after blocking uptake. This effect was quantified by measuring the extent of depression, expressed as the amplitude of the 10th divided by the amplitude of the first EPSC in a train $\left(P_{10} / P_{1}\right)$, as a function of stimulus frequency. Data were collected over a range from 0.03 to $600 \mathrm{~Hz}$ to determine the frequencydependence of the action of transporters. As shown in Figure 2, $C$ and $D$, no effect on depression was evident until the stimulus rate exceeded $10 \mathrm{~Hz}$. Above this frequency, blockade of transporters significantly enhanced depression, with the largest effects seen at the highest stimulus rates at which measurable responses could be obtained (Fig. 2E, gray bars). For comparison, we also measured the effect of antagonists on the paired-pulse depression
$(P 2 / P 1)$. The second EPSC also showed greater depression in the presence of uptake blockers but less than that observed during lengthier stimulus trains (Fig. 2E, open bars).

\section{Suprathreshold transmission}

To explore further the effects of the antagonists on synaptic strength, neurons were current clamped, and trains of 20 presynaptic stimuli were delivered at different frequencies. Figure $3, A$ and $B$, shows that EPSPs remained suprathreshold at $100 \mathrm{~Hz}$, even in the presence of the uptake blockers, a consequence of the high safety factor for transmission in nMag (Brenowitz et al., 1998). However, at $173 \mathrm{~Hz}$, EPSPs in THA+DHK immediately fell subthreshold, whereas control EPSPs still evoked action potentials. At still higher rates, neither experimental or control EPSPs were consistently suprathreshold, although it was evident that the control EPSPs were larger. Figure $3 C$ quantifies the probability of suprathreshold transmission over the second half of the train, showing that there was a cutoff frequency above which EPSPs fail to evoke spikes and that block of uptake shifts the cutoff to lower frequencies. Because nMag neurons are innervated by two to three auditory nerve axons (Jackson and Parks, 1982) and the EPSPs they elicit may summate (Zhang and Trussell, 1994a), this cutoff presumably occurs at higher frequencies in vivo.

Inhibition of glutamate uptake also had effects on the timing of transmission for EPSPs that remained suprathreshold. Figure $4 \mathrm{~A}$ shows that the size and shape of the first orthodromic action potential in a $100 \mathrm{~Hz}$ train is unaltered by THA+DHK (control shown in gray), whereas the 20th response is smaller and peaks 

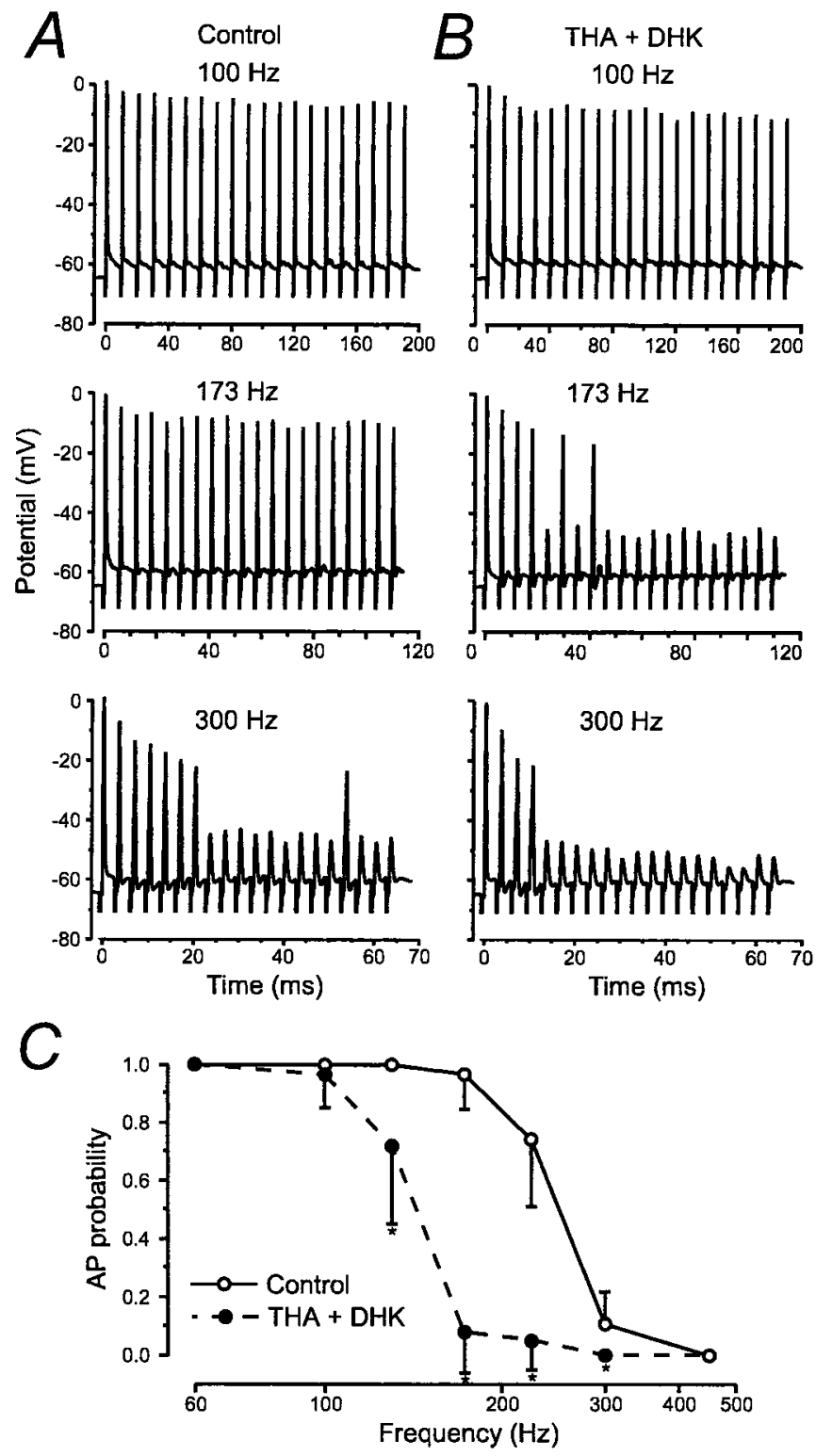

Figure 3. Antagonists of transporters reduce synaptic strength. $A, B$, Orthodromic action potentials in control and THA+DHK solutions, as indicated. Subthreshold EPSPs become apparent at $173 \mathrm{~Hz}$ when uptake is blocked. $C$, Average action potential probability at different frequencies in control and THA +DHK. Asterisks indicate significant difference from control $(p<0.01) \cdot n=7-16$ for different frequencies. Action potential probability was determined by averaging successes (1) or failures (0) for the last 10 responses in trains of 20 stimuli.

slightly later. Because the ipsilateral and contralateral nMag must maintain action potential timing with a precision of hundreds of microseconds (Hyson et al., 1994), we quantified this shift in action potential latency in Figure $4 B$. The difference in timing of the action potential peak in control and THA+DHK solutions was measured for the 1st and 20th responses and plotted as a function of stimulus frequency. Although the first response was unaffected by the antagonists, the 20th occurred at progressively later times as frequency was increased, such that by $173 \mathrm{~Hz}$, spikes were delayed by nearly $200 \mu \mathrm{sec}$. This increase in latency was presumably because of the reduction in amplitude of the EPSP and a consequent delay in when threshold was reached (Zhang and Trussell, 1994a). The variability in the latency of action potentials later in the train was also higher in uptake blockers (Fig. $4 C$ ); this effect is quantified in Figure $4 D$ as the SD of the timing of the peaks of the last 10 orthodromic action potentials evoked in the two experimental conditions.

\section{Accumulation of glutamate during trains of stimuli}

Evidence that glutamate accumulated in the synaptic cleft during trains of stimuli came from analysis of the amplitude of currents just preceding each response in the train and the current decay after the train. As shown in Figure $5 A$ (dashed line), a current "plateau" was apparent between each response; this plateau was increased in the presence of THA+DHK (Fig. 5B). Moreover, after the train, current decayed more gradually when transporters were blocked (Fig. 5A). This slower decay was not attributable to an enhancement of slow-acting NMDA receptors, because these receptors were blocked by competitive and noncompetitive antagonists (see Materials and Methods) and because the amplitude of the slow decay phase relative to the peak current was not sensitive to holding potential (Fig. $5 A$, inset). Figure $5 C$ shows that the plateau was larger at higher stimulus frequencies but that the enhancement produced by $\mathrm{THA}+\mathrm{DHK}$ was approximately similar between 30 and $600 \mathrm{~Hz}$.

The decay of EPSCs after a train in the presence of THA+DHK was often not exponential but exhibited a slight hump that made exponential curve fitting imprecise (Fig. $5 A$, black trace). Therefore, we quantified the decay time after the train by measuring the time for the current level just preceding the last response in the train to decay by $50 \%$. This analysis showed that the decay time of the slow phase of the last EPSC in a train was significantly longer in THA+DHK. Moreover, whereas the decay after the train in control solutions was faster for higher frequency trains, in THA + DHK the decay time was constant between 30 and $600 \mathrm{~Hz}$ (Fig. $5 F$ ). We interpret the acceleration in decay in control solution to reflect a declining amount of transmitter release on each stimulus with increasing frequency (Trussell et al., 1993; Zhang and Trussell, 1994b); less release would not tax the capacity of transporters as much, and thus clearance would be faster. The fact that only after block of transport was this decay time similar at all frequencies suggests that a balance was achieved between progressive accumulation of glutamate and a declining release per stimulus, generating a similar average amount of transmitter after the train. This conclusion is supported by comparison of the decay time after single stimuli versus trains, with and without THA + DHK. Figure 5, $D$ and $E$, shows that, whereas in control solutions the slow phase of decay (arrow) was faster after trains compared with single responses (gray trace), the slow phase after the train lasted longer than the single response when uptake was inhibited. These results suggest that reduction in uptake caused a pooling of transmitter, resulting in repeated rebinding of glutamate to AMPA receptors.

\section{Postsynaptic locus of increased depression}

The enhancement of depression and its effects on spike probability and timing could be a result of either the action of glutamate on presynaptic metabotropic glutamate receptors (mGluRs), which inhibit release in some auditory neurons (Barnes-Davies and Forsythe, 1995; von Gersdorff et al., 1997), or the enhancement of desensitization of postsynaptic AMPA receptors. The former possibility seemed unlikely because previous studies have shown that a selective agonist of some mGluRs, ( \pm )-1aminocyclopentane-trans-1,3-dicarboxylic acid, had little effect on EPSCs in nMag (Otis and Trussell, 1996), at least at room 

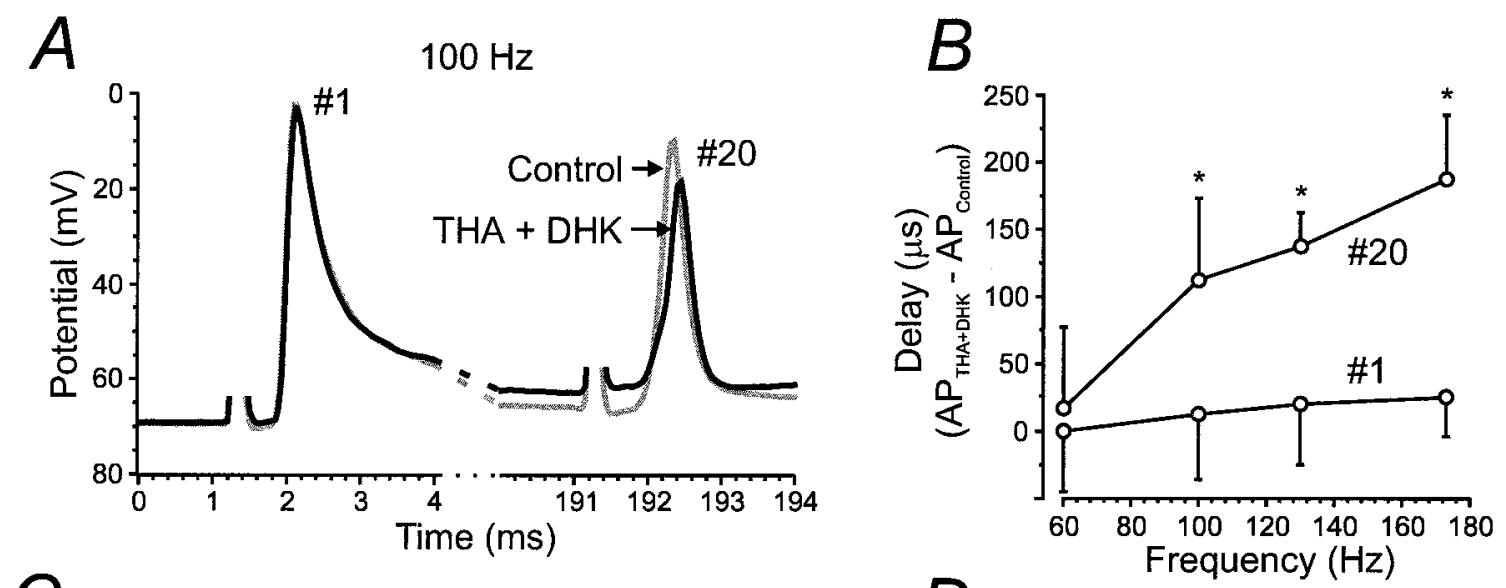

Q
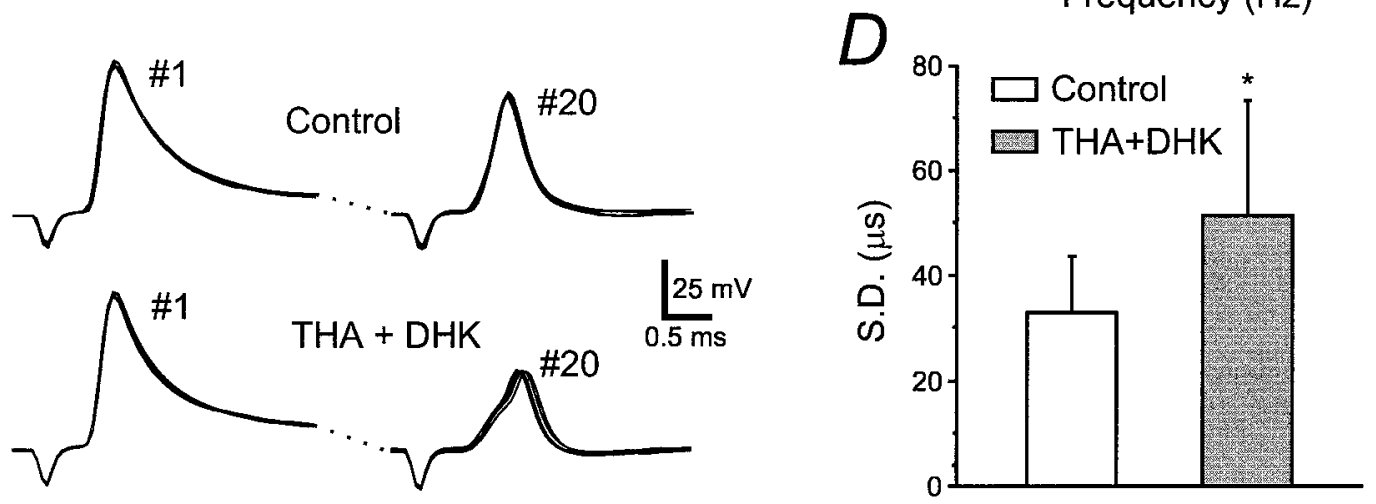

Figure 4. Effects of uptake blockers on the timing of orthodromic action potentials. $A$, First and 20th synaptically driven action potentials in a $100 \mathrm{~Hz}$ train, with (black) and without ( gray) THA+DHK. Note slight reduction and delay in spike during antagonist application. $B$, Difference in timing of 1 st and 20th action potentials in trains delivered at different rates. At the higher rates, the suprathreshold spikes occurred with a delay nearly $200 \mu$ sec longer in the presence of blockers. $n=6-12$. $C$, Jitter in timing of action potentials at the end of trains increased in the presence of antagonists. $D$, SD of timing of peaks of last 10 orthodromic action potentials in $100 \mathrm{~Hz}$ train of 20 stimuli was significantly increased in THA+DHK. $n=6-12$ per frequency.

temperature. This was confirmed in the present study using another mGluR agonist, L(+)-2-amino-4-phosphonobutyric acid (LAP-4). Bath or pressure ejection application of L-AP-4 at $100 \mu \mathrm{M}$ had no effect on either the baseline holding current or the amplitude of EPSCs (drug/control values, $0.98 \pm 0.11$ and $0.99 \pm$ 0.03 , respectively; $n=4$ cells). In contrast, the presynaptic $\mathrm{GABA}_{\mathrm{B}}$ agonist baclofen was able to strongly depress release in the same preparation (Brenowitz et al., 1998). Because there does not appear to be presynaptic control of release by metabotropic glutamate receptors, it seems unlikely that accumulation of glutamate in THA+DHK acted presynaptically.

This conclusion was confirmed by examining the actions of $\mathrm{THA}+\mathrm{DHK}$ in the presence of a blocker of AMPA receptor desensitization, cyclothiazide. In nMag, cyclothiazide prolongs the decay of EPSCs and reduces the extent of synaptic depression (Trussell et al., 1993). In five of six neurons, cyclothiazide (100 $\mu \mathrm{M})$ inhibited paired-pulse depression (10 msec stimulus interval), expressed as the response 2/response 1 amplitude ratio, from $0.40 \pm 0.20$ to $0.62 \pm 0.20$. In these same cells, application of $\mathrm{THA}+\mathrm{DHK}$ in the continued presence of cyclothiazide had no significant effect on depression for either the 2 nd or 10 th response in a $100 \mathrm{~Hz}$ train $(p=0.09$ and 0.40 , respectively). Figure 6 illustrates these effects in one cell, showing the decrease in depression after application of cyclothiazide (Fig. 6A,B) and the relatively small differences between the amplitudes of EPSCs before and after adding uptake blockers while in a background of cyclothiazide (Fig. 6B,C). Although it has been proposed that cyclothiazide may have additional presynaptic actions (Diamond and Jahr, 1995; Bellingham and Walmsley, 1999), the postsynaptic action of the drug on AMPA receptors is well established (Patneau et al., 1993; Yamada and Tang 1993), and our experimental paradigm should not be sensitive to presynaptic actions of the drug on vesicle release mechanisms. Thus, under these experimental conditions, the proclivity of AMPA receptors to desensitize, the absence of an effect of THA +DHK on depression when cyclothiazide was present, and the apparent lack of presynaptic metabotropic glutamate receptors together indicate that glutamate accumulation enhances depression through increase in desensitization.

\section{Action of a glutamate scavenger}

GPT has been used in previous studies to scavenge synaptically released glutamate (O'Brien and Fischbach, 1986; Rossi and Slater, 1993; Min et al., 1998). In the present work, GPT was used to determine whether or not glutamate accumulates during stimulus trains when transporters are active. The prediction was that, if accumulating glutamate contributed to synaptic depression, then lessening this accumulation by GPT should reduce the extent of depression. Application of GPT at 5-10 U/ml in the presence of 2-4 mM pyruvic acid (see Materials and Methods) had no effect on the amplitude of low-frequency EPSCs (GPT/ control amplitudes, $0.96 \pm 0.11 ; n=8$ cells) (Fig. $6 A, B$ ). However, examination of the decay of EPSCs showed that GPT accelerated the slow phase of decay, as illustrated in Figure 6, $C$ 

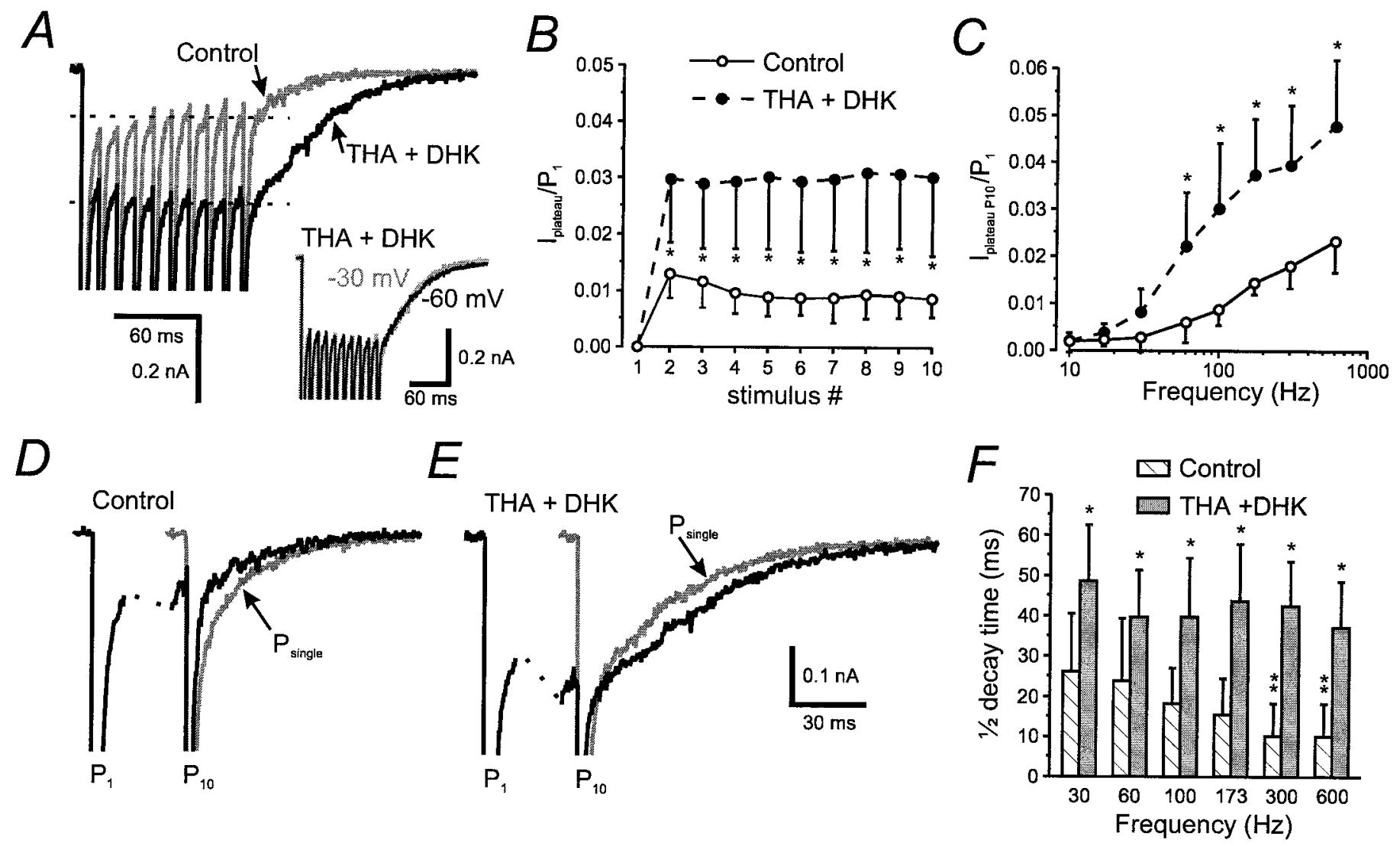

Figure 5. Evidence for accumulation of glutamate during trains when transporters are blocked. A, Plateau current (marked by dashed line) between EPSCs in a train $(100 \mathrm{~Hz})$ is increased in THA+DHK. Average of three traces. Moreover, the current decay after the train is prolonged. Inset, Train recorded at -60 and $-30 \mathrm{mV}$ was scaled to the amplitude of the first EPSC and superimposed. The overlap of the decay indicates that the slowed decay does not reflect enhanced activation of NMDA receptors by residual glutamate. $B$, Amplitude of the current plateau versus stimulus number in a 100 $\mathrm{Hz}$ train for control and THA+DHK solutions. Amplitudes measured in the $1 \mathrm{msec}$ period just before each stimulus in the train and normalized to the amplitude of the peak of the first EPSC. Asterisk indicates significant difference from control $(p<0.02)$. $C$, Increase in current plateau with stimulus frequency. Current level just before final EPSC was measured as in $B(p<0.03)$. $D, E$, Comparison of the decay of current after the 10 th response in a $100 \mathrm{~Hz}$ train to the decay after a single response, for control and uptake blocker solutions. Note that the decay of the single response is slower in control solutions but relatively faster after uptake blockade. $F$, Decay time after 10th EPSC in a train delivered at the indicated frequencies. Decay was measured as time necessary for $50 \%$ decay current amplitude measured $1 \mathrm{msec}$ before the last stimulus in the train. Single asterisks indicate significant difference of THA +DHK solutions from control solution $(p<0.02)$, and double asterisks indicate significance of control high-frequency responses from responses at $30 \mathrm{~Hz}(p<0.01) \cdot n=7-13$ cells.

and $D$, with no effect on the relative weights of the exponential components (data not shown). Because this slow phase was attributed to rebinding of glutamate and was enhanced by $\mathrm{THA}+\mathrm{DHK}$, this action of GPT indicates that residual glutamate is present even with normal transporter activity. We then examined the action of GPT on the response to trains of stimuli at $173 \mathrm{~Hz}$ and found that the enzyme significantly reduced the extent of depression during trains, for both the 2nd and 10th EPSC in a stimulus train, as shown in Figure 7. Although there was no measurable effect of GPT on the plateau current between responses in a train, GPT did reversibly accelerate the decay of current after the train, from $14.42 \pm 6.22 \mathrm{msec}$ in control to $9.56 \pm 1.99 \mathrm{msec}$ in GPT $(p<0.05 ; n=8)$. Thus, the activity of glutamate transporters is not adequate to completely remove glutamate in the synaptic cleft sufficiently fast to prevent some desensitization of AMPA receptors.

In a second set of experiments, a higher concentration of GPT was used to see whether the glutamate transient could be further accelerated. Using GPT at a concentration of 40-60 U/ml in the presence of 10-20 mM pyruvate, results were obtained that were similar to those with the lower GPT concentration, except that the amplitude of the first response in a train was reduced to $0.81 \pm 0.26$ of control $(p<0.05 ; n=18)$. In control experiments, GPT at $40 \mathrm{U} / \mathrm{ml}$ in the absence of pyruvate $(n=5)$ or application of $16 \mathrm{~mm}$ pyruvate alone $(n=5)$ produced no significant effect on amplitude and decay time course of single EPSCs or on the amount of depression, the plateau current or the decay after a 173 $\mathrm{Hz}$ train.

Finally, we examined the effect of GPT at 40-60 U/ml on the time course of single EPSCs and extent of depression seen in the presence of THA+DHK. As observed above, THA+DHK significantly increased the decay time of the third exponential component of single EPSCs from $17.8 \pm 5.3$ to $42.5 \pm 21.0 \mathrm{msec}(p<$ 0.01 ), whereas in GPT plus THA + DHK the decay constant was $27.0 \pm 17.5 \mathrm{msec}$, which was significantly different from the decay constant in THA+DHK ( $p<0.01 ; n=8$ cells) but not from control. The amplitude of single EPSCs in THA+DHK was $99.5 \pm 4.1 \%$ of control amplitude, whereas in GPT plus THA + DHK it was $85.1 \pm 14.7 \%$ of the peak amplitude in THA + DHK $(p<0.01 ; n=11)$. GPT was not able to accelerate the decay of current after a $173 \mathrm{~Hz}$ train of stimuli in the presence of uptake blockers, nor did it antagonize the effects of blockers on 


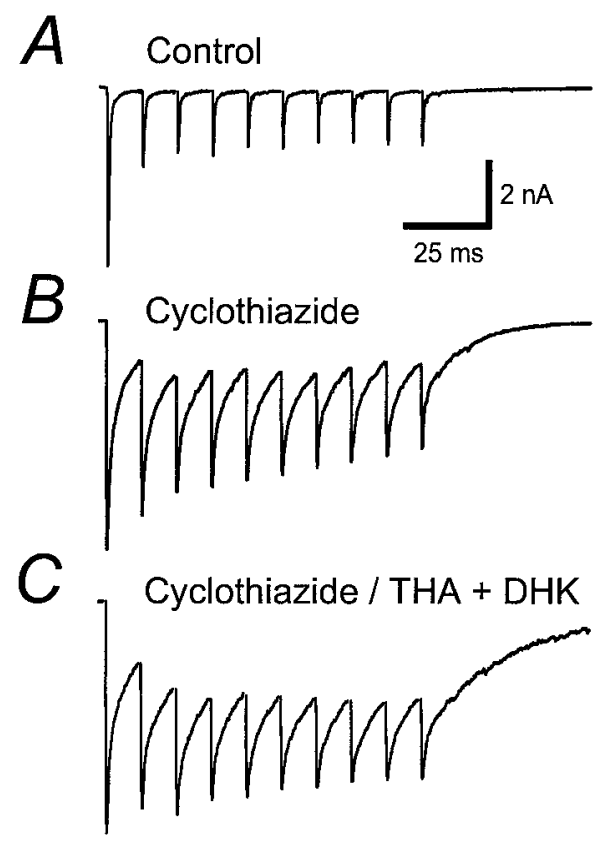

Figure 6. Effects of uptake blockers in the presence of cyclothiazide. $A$, Control responses to train of 10 shocks at $100 \mathrm{~Hz}$. $B$, In the same cell after application of $100 \mu \mathrm{M}$ cyclothiazide, the first EPSC is only slightly larger, but subsequent EPSCs are markedly enhanced, reflecting the reduction of depression induced by cyclothiazide. $C$, Addition of THA+DHK did not significantly increase depression over that seen in $B$. the plateau current during the train beyond the 15-20\% inhibition, which was also observed for the peak response. However, GPT did antagonize the effects of blockers on depression. The extent of depression $\left(P_{10} / P_{1}\right)$ at $173 \mathrm{~Hz}$ was $0.14 \pm 0.10$ in control, $0.08 \pm 0.07(p<0.01)$ in THA + DHK, but only $0.13 \pm 0.09$ in GPT plus THA+DHK $(p<0.02$ for difference from THA+DHK; $n=9$ ). Thus, although the apparent effectiveness of GPT diminished when transporters were blocked, GPT was still able to reduce glutamate enough to oppose postsynaptic depression.

\section{Sites of glutamate uptake}

The site of glutamate uptake was identified by taking advantage of the current generated by glutamate transporters, which is a combination of ionic flux coupled to the transport process and of nonstoichiometric flux through an anion channel gated by the transporter (Otis and Kavanaugh, 1999). We maximized both sources of current by loading cells with a $\mathrm{KNO}_{3}$ solution, which has been shown to produce large currents during activation of cloned and native glutamate transporters (Wadiche et al., 1995; Bergles and Jahr, 1997; Bergles et al., 1997; Otis and Jahr, 1998). Glutamate $(1 \mathrm{~mm})$ was pressure applied for $100 \mathrm{msec}$ to cells in the continuous presence of antagonists of AMPA and NMDA receptors (see Materials and Methods), so that the resulting currents were likely to be associated with transporter activity. In the first set of experiments, currents were recorded from small cells adjacent to nMag neurons (see Materials and Methods). In previous studies, many of these cells were immunoreactive for GFAP (Canady et al., 1994), an astrocyte-specific marker. We
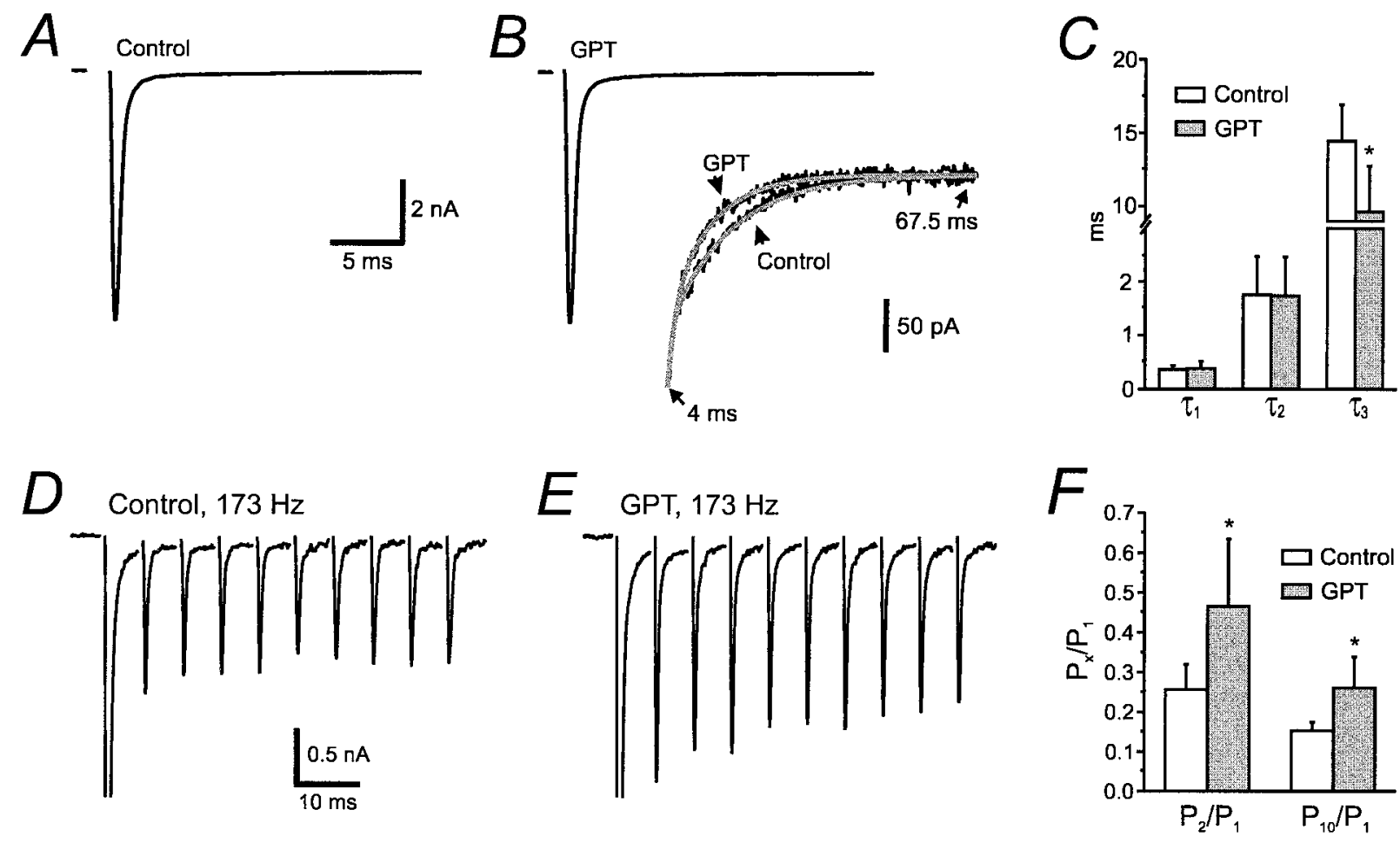

Figure 7. Actions of GPT. $A, B$, EPSCs from one cell in control and $10 \mathrm{U} / \mathrm{ml} \mathrm{GPT}$ solution. Inset in $B$ shows an overlay of these two traces, revealing a faster decay phase in the presence of GPT. $C$, The time constants obtained for three-exponential fits with and without GPT (asterisk indicates difference from control; $p<0.01 ; n=8$ ). The third exponential component was significantly shorter in GPT, although the relative weights of the components were unchanged (data not shown). $D, E$, Trains in one cell show less depression in GPT. Peak amplitudes of the first EPSC are cutoff. $F$, Average behavior for degree of depression for 2nd and 10th EPSC in a train delivered at $173 \mathrm{~Hz}$, with and without GPT. $n=8$ cells; $p<0.01$. In three of these eight cases, the enzyme was washed out and reversibility demonstrated. 


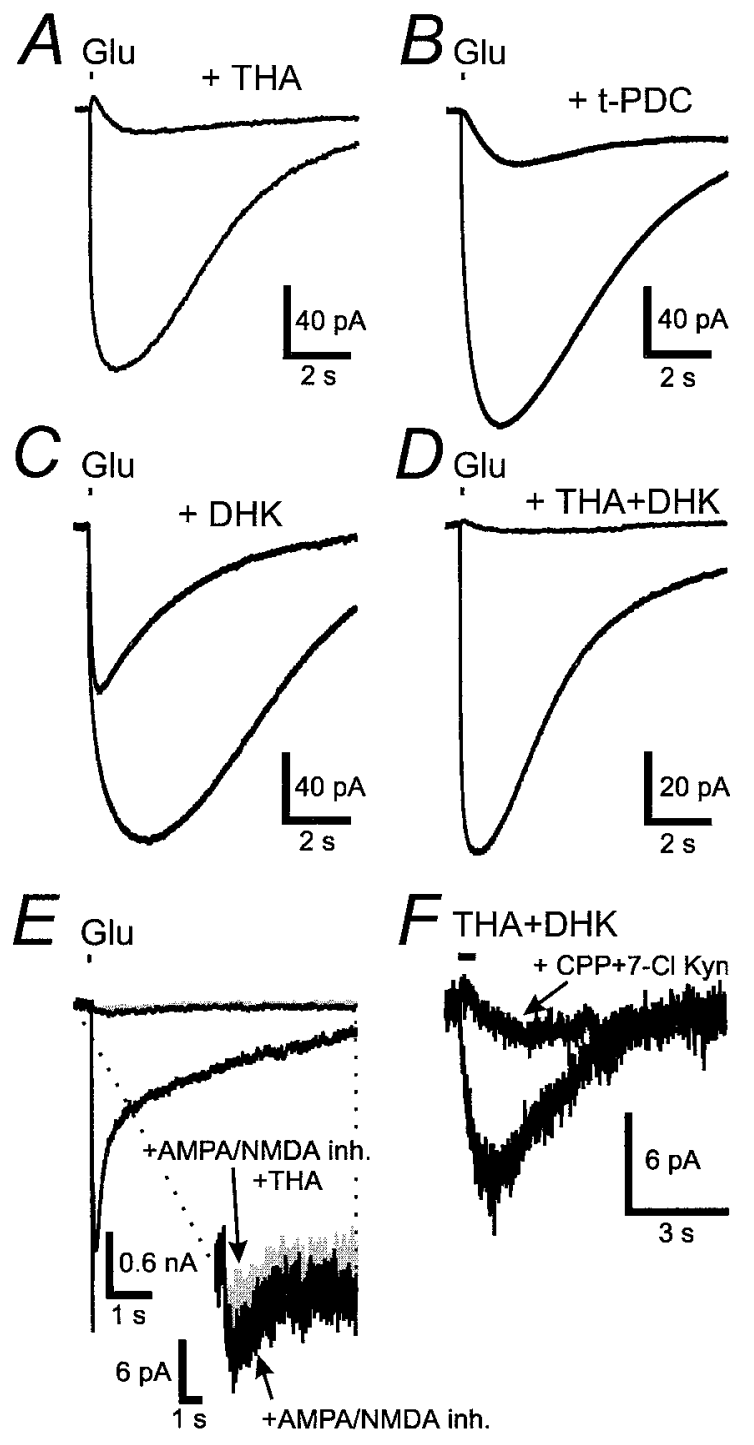

Figure 8. Responses of neurons and glia to glutamate application. $A-D$ shows glial cell responses to a $100 \mathrm{msec}$ puff of $1 \mathrm{~mm}$ glutamate in the presence and absence of the indicated antagonist, all at $300 \mu \mathrm{M}$. Holding potential was $-70 \mathrm{mV}$, and pipette contained a $\mathrm{KNO}_{3}$ solution (see Materials and Methods). Offsets generated by direct activity of the antagonist on transporters were removed to illustrate reduction in glutamate response. These values were $-240(A),-350(B),+90(C)$, and $-50(D)$ pA. $E$, Effect of glutamate application on a $\mathrm{KNO}_{3}$-filled nMag neuron. Largest response is in control bath solution, and two small responses are after block of ionotropic glutamate receptors as in Materials and Methods. Spike-like transient is caused by rapid desensitization of glutamate receptors. Inset amplifies responses in receptor blockers, showing that the residual response is small and only weakly sensitive to THA. $F$, THA+DHK cocktail (500 msec puff) alone produced a small inward current in a $\mathrm{CsMeSO}_{3}$-filled neuron, which was antagonized by NMDA receptor antagonists $(n=4)$. All panels show data from different cells. All recordings made in $1 \mu \mathrm{M}$ TTX.

therefore compared their response with that of neurons with application of glutamate.

Figure $8 A-D$ shows the response of glial cells held at $-70 \mathrm{mV}$ to brief application of glutamate and the effect of blockers of glutamate transporters. Glutamate evoked a slow inward current in every glial cell tested (average peak response of $-114 \pm 14 \mathrm{pA}$; 23 cells). These currents were reversibly blocked by $300 \mu \mathrm{M}$ THA (control, $-119 \pm 43$ pA; THA, $-8 \pm 5$ pA; 4 cells) (Fig. $8 A$ ), by
$300 \mu \mathrm{M}$ L-trans-pyrollidine-2,4-dicarboxylic acid (t-PDC) (control, $-104 \pm 52$ pA; t-PDC, $-16 \pm 14$ pA; 4 cells) (Fig. 8 B) and by 300 $\mu \mathrm{M}$ DHK (control, $-127 \pm 40 \mathrm{pA}$; DHK, $-83 \pm 10 \mathrm{pA} ; 5$ cells) (Fig. $8 C$ ). These effects were significant for all compounds $(p<$ $0.05)$. The THA+DHK mixture used above was most effective, reducing $>96 \%$ of the inward current induced by glutamate (control, $-104 \pm 27 \mathrm{pA}$; THA + DHK, $-4 \pm 2$ pA; 5 cells) (Fig. $8 D$ ). As shown in Figure $8 E$, application of $1 \mathrm{~mm}$ glutamate to nMag neurons in the presence of AMPA and NMDA receptor antagonists and internally perfused with a $\mathrm{KNO}_{3}$ solution (see Materials and Methods) produced currents $<10 \mathrm{pA}$, and these were relatively insensitive to THA $(n=10)$. Unlike cerebellar Purkinje cells (Kataoka et al., 1997; Otis et al., 1997), nMag neurons do not express a significant level of functional glutamate transporters. Because glial cell processes in nMag are adjacent to, or inserted into, the end-bulb synapse (Parks, 1981), it seems likely that they provide a significant site of glutamate transport in vivo.

\section{DISCUSSION}

\section{Control of glutamate transients in the synaptic cleft}

Synaptic depression has been attributed to a variety of factors, including transmitter depletion (von Gersdorff et al., 1997), refractoriness of release (Bellingham and Walmsley, 1999), inactivation of calcium current (Forsythe et al., 1998), activation of presynaptic autoreceptors (Barnes-Davies and Forsythe, 1995; von Gersdorff et al., 1997), postsynaptic receptor desensitization (Trussell et al., 1993; Otis et al., 1996a), and use-dependent inactivation of receptors (Tong et al., 1995). The latter three mechanisms are sensitive to the effectiveness of clearance of transmitter, such that a delay in clearance, and the resultant pooling of transmitter during repetitive activity, will enhance depression. At the end-bulb synapse in nMag, the concentration of release sites compounds the problems of clearance faced by the glutamatergic synapse (Otis et al., 1996b). Inhibition of glutamate transporters at this synapse impedes clearance, yet only slightly slows the decay of the EPSC. Presumably, the faster components of the EPSC do not reflect the clearance process itself, but rather the kinetics of gating and unbinding or desensitizing the AMPA receptor-channel complex, as well as the time course of vesicle fusion (Diamond and Jahr, 1995; Isaacson and Walmsley, 1995; Otis and Trussell, 1996). As noted previously, the slower component is best explained as tracking the delayed clearance of a low concentration of glutamate from the cleft. That the slow decay phase is attributable to rebinding of transmitter to AMPA receptors was demonstrated here and in previous experiments, which showed block of the slow phase by CNQX (Otis et al., 1996b), the similarity in its current-voltage relationship to steady-state AMPA responses (Otis et al., 1996b), its persistence in NMDA receptor antagonists, the lack of effect of mGluR agonists, and the comparatively rapid binding and unbinding kinetics of AMPA receptors (Raman and Trussell, 1995a). Although this tail of glutamate is far lower than the peak concentrations achieved in the synaptic cleft, it is significant that only low micromolar levels are needed to desensitize AMPA receptors (Raman and Trussell, 1992) and therefore that residual glutamate could play a significant role in the ongoing regulation of synaptic strength. In the absence of uptake, EPSCs decayed more slowly after a train than after a single stimulus, despite the reduction in transmitter release, indicating a progressive accumulation of transmitter and its rebinding to AMPA receptors. However, when transporters were active, the decay was faster after a high-frequency train, suggest- 
ing that transporters play a vital role in removing glutamate on a per stimulus basis.

Our results are similar in part to the recent study of Overstreet et al. (1999), who examined the effect of transport blockers in the large synapse of the unipolar brush cell. Although no effects were reported in that study on the peaks of EPSCs during trains, t-PDC slowed the decay of current after a train of synaptic stimuli, increasing the total charge transfer significantly. The postsynaptic granule cell then integrated the extra charge, resulting in increased firing. In contrast, the auditory neurons we studied here fire only on the peak of each EPSP; thus, they were more sensitive to effects on peak depression than on the change in the shape of each response and so the net effect of transport blockade was inhibitory. These differences highlight the importance of interpreting transporter action in the context of membrane specializations characteristic of different neuronal pathways.

\section{Role of glial cells}

Large glutamate transporter-dependent currents were observed in glial cells attached to nMag neuronal cell bodies. These responses were blocked only partially by a relatively high concentration of DHK, suggesting that these cells express both GLAST and GLT-1, glial isoforms of transporter that differ in their pharmacological sensitivities (Gegelashvili and Schoesboe, 1998). Initial attempts to record synaptically induced glial transporter currents, as has been performed in hippocampus and cerebellum (Bergles and Jahr, 1997; Bergles et al., 1997; Clark and Barbour, 1997), were only rarely successful, suggesting that only a small fraction of the processes of any individual glial cell enshroud a given axon terminal in this preparation. However, it may also be that transporter activity resides in the presynaptic terminal; if so, such uptake could significantly abbreviate glutamate transients on a fast time scale (Tong and Jahr, 1994).

Although the accumulation of glutamate and its effect on depression depend critically on the frequency of glutamate release, the effects of transporter blockers were maximal in the physiological range of firing. Thus, modulation of transport by glial cells could be a significant point of regulation of synaptic strength in vivo. It has been shown that glial cells in nMag respond to cessation of auditory nerve transmission by proliferation of processes (Canady et al., 1994); more subtle, dynamic control of glial processes or transporter efficacy could prove important to auditory signaling. For example, we have shown that downregulation of transport shifts the "cutoff" of suprathreshold transmission to lower frequencies. In principle, it might also shift to higher frequencies with enhancement of transport rate. It is important to note that nMag synapses fire spontaneously, in the quiet, at $\sim 100$ $\mathrm{Hz}$, and presynaptic fibers are driven briefly by acoustic stimuli to nearly $400 \mathrm{~Hz}$ (Warchol and Dallos, 1990; Chen et al., 1996). Thus, considering the frequency range over which the uptake blockers exerted their effect (Fig. 2D), these data indicate that transporters are likely to maintain significant control over synaptic strength in vivo.

The potential for upregulation of transporter activity to increase synaptic strength is underscored by our observation that the glutamate scavenger GPT was able to reduce depression and accelerate the decay of the EPSC, with only minor effect on the amplitude of the first EPSC in a train. This indicates that, under normal conditions, at temperatures only slightly below normal (37 vs $41^{\circ} \mathrm{C}$ ), glutamate transporters, although critical for synaptic function, are not able to eliminate immediately and completely the large volume of transmitter released from the end-bulb synapse. This point has bearing on the mechanisms of desensitization induced by synaptically released glutamate. AMPA receptors desensitize upon repeated binding to glutamate. However, because desensitization is rapid and can proceed even from partially liganded, closed states of the channel (Raman and Trussell, 1995b), it has been uncertain whether the synaptically induced desensitization we have observed previously requires prolonged glutamate exposure or whether it happens upon its initial exposure to transmitter. The present results indicate that at least some glutamate must persist in the cleft and cause desensitization by repeated activation of the receptor.

\section{Effectiveness of GPT}

Neither blockade of glutamate transport nor enhancement of glutamate degradation with low concentrations of GPT altered the peak of single EPSCs; only with high concentrations of GPT was the peak slightly reduced. Regarding GPT, this result is not surprising considering the low capacity of GPT to consume glutamate. At a turnover rate of $1100 / \mathrm{sec}$ and a concentration of 60 $\mathrm{U} / \mathrm{ml}$, GPT should reduce the glutamate concentration by 14 $\mu \mathrm{M} / \mathrm{msec}$, assuming $2 \mathrm{~mol}$ of glutamate per GPT molecule (Gatehouse et al., 1967; Jenkins and Saier, 1970). With a peak glutamate transient of $\sim 6 \mathrm{~mm}$ (Otis et al., 1996a), this level should have only a minor effect on the peak EPSC. GPT also did not reduce the plateau current between EPSCs in a train, although this may simply reflect the signal-to-noise ratio; because the largest difference in current between GPT and control single EPSC decay phases was only $\sim 20 \mathrm{pA}$ (Fig. 6), the reduction of the current between ongoing, fluctuating EPSCs would not be easily resolved.

Another issue is that the nMag EPSC, even at its peak, is influenced by cross-talk among clusters of release sites (Otis et al., 1996a). Thus, factors that influence accessibility of glutamate to adjacent synapses could markedly alter the synaptic response. Although the capacity of our GPT solutions for glutamate degradation is relatively low, it may be sufficient to alter the peak EPSC by impeding or slowing cross-talk. This point is also relevant to why block of transport did not alter the peak of single EPSCs, in contrast to what was observed in hippocampal cultures (Tong and Jahr, 1994). If glutamate transporters located on glial cell processes are interposed between clusters of release sites rather than between each individual site, then transport blockers would only be effective on glutamate transients generated by the aggregate activity of multiple synapses.

In the presence of uptake blockers, GPT was less effective. Although still able to reduce depression, current decay after trains was not accelerated. Yet clearly the enzyme was active, because it altered depression, and in the absence of uptake blockers hastened current decay. This result may give insight into the levels of glutamate in the cleft during these experimental conditions. The steady-state dose-response relationship for glutamate in nMag is biphasic, with a peak between 70 and $100 \mu \mathrm{M}$ (Raman and Trussell, 1992). Reduction in glutamate levels through the 70-200 $\mu \mathrm{M}$ range might be expected to influence the occupancy of receptors, and so alter desensitization, yet produce little decrease (or even an increase) in the plateaus and slow phases of EPSCs that we measured. That, plus the fact that little desensitization occurs with less than $\sim 1 \mu \mathrm{M}$ glutamate (Raman and Trussell, 1992), suggests that alterations in slow currents observed with GPT and without uptake blockers probably reflected actions in the range of 1-70 $\mu \mathrm{M}$ glutamate. 


\section{REFERENCES}

Barnes-Davies M, Forsythe ID (1995) Pre- and postsynaptic glutamate receptors at a giant excitatory synapse in rat auditory brainstem slices. J Physiol (Lond) 488:387-406.

Bellingham MC, Walmsley B (1999) A novel presynaptic inhibitory mechanism underlies paired pulse depression at a fast central synapse. Neuron 23:159-170.

Bergles DE, Jahr CE (1997) Synaptic activation of glutamate transporters in hippocampal astrocytes. Neuron 19:1297-1308.

Bergles DE, Dzubay JA, Jahr CE (1997) Glutamate transporter currents in bergmann glial cells follow the time course of extrasynaptic glutamate. Proc Natl Acad Sci USA 94:14821-14825.

Brenowitz S, David J, Trussell L (1998) Enhancement of synaptic efficacy by presynaptic GABA(B) receptors. Neuron 20:135-141.

Canady KS, Hyson RL, Rubel EW (1994) The astrocytic response to afferent activity blockade in chick nucleus magnocellularis is independent of synaptic activation, age, and neuronal survival. J Neurosci 14:5973-5985.

Chen L, Trautwein PG, Shero M, Salvi RJ (1996) Tuning, spontaneous activity and tonotopic map in chicken cochlear ganglion neurons following sound-induced hair cell loss and regeneration. Hear Res 98:152-164.

Clark BA, Barbour B (1997) Currents evoked in Bergmann glial cells by parallel fibre stimulation in rat cerebellar slices. J Physiol (Lond) 502:335-350.

Diamond JS, Jahr CE (1995) Asynchronous release of synaptic vesicles determines the time course of the AMPA receptor-mediated EPSC. Neuron 15:1097-1107.

Forsythe ID, Tsujimoto T, Barnes-Davies M, Cuttle MF, Takahashi T (1998) Inactivation of presynaptic calcium current contributes to synaptic depression at a fast central synapse. Neuron 20:797-807.

Gatehouse PW, Hopper S, Schatz L, Segal HL (1967) Further characterization of alanine aminotransferase of rat liver. J Biol Chem 242:2319-2324.

Gegelashvili G, Schousboe A (1998) Cellular distribution and kinetic properties of high-affinity glutamate transporters. Brain Res Bull 45:233-238.

Hyson RL Overholt EM, Lippe WR (1994) Cochlear microphonic measurements of interaural time differences in the chick. Hear Res 81:109-118.

Isaacson JS, Walmsley B (1995) Counting quanta: direct measurements of transmitter release at a central synapse. Neuron 15:875-884.

Jackson H, Parks TN (1982) Functional synapse elimination in the developing avian cochlear nucleus with simultaneous reduction in cochlear nerve axon branching. J Neurosci 2:1736-1743.

Jenkins WT, Saier M (1970) L-Alanine aminotransferase (pig heart). Methods Enzymol 17A:159-163.

Kataoka Y, Morii H, Watanabe Y, Ohmori H (1997) A postsynaptic excitatory amino acid transporter with chloride conductance functionally regulated by neuronal activity in cerebellar Purkinje cells. J Neurosci 17:7017-7024

Maki R, Robinson MB, Dichter MA (1994) The glutamate uptake inhibitor L-trans-pyrrolidine-2,4-dicarboxylate depresses excitatory synaptic transmission via a presynaptic mechanism in cultured hippocampal neurons. J Neurosci 14:6754-6762.

Min M-Y, Rusakov DA, Kullmann DM (1998) Activation of AMPA, kainate, and metabotropic receptors at hippocampal mossy fiber synapses: role of glutamate diffusion. Neuron 21:561-570.

O'Brien RJ, Fischbach GD (1986) Modulation of embryonic chick motoneuron glutamate sensitivity by interneurons and agonists. J Neurosci 6:3290-3296.

Otis TS, Jahr CE (1998) Anion currents and predicted glutamate flux through a neuronal glutamate transporter. J Neurosci 18:7099-7110.

Otis TS, Kavanaugh MP (1999) Glutamate transporters and their contributions to excitatory synaptic transmission. In: Ionotropic glutamate receptors in the CNS (Jonas P, Monyer H, eds), pp 419-440. Heidelberg, Germany: Springer.

Otis TS, Trussell LO (1996) Inhibition of transmitter release shortens the duration of the excitatory synaptic current at a calyceal synapse. J Neurophysiol 76:3584-3588.
Otis T, Zhang S, Trussell LO (1996a) Direct measurement of AMPA receptor desensitization induced by glutamatergic synaptic transmission. J Neurosci 16:7496-7504.

Otis TS, Wu YC, Trussell LO (1996b) Delayed clearance of transmitter and the role of glutamate transporters at synapses with multiple release sites. J Neurosci 16:1634-1644.

Otis TS, Kavanaugh MP, Jahr CE (1997) Postsynaptic glutamate transport at the climbing fiber-Purkinje cell synapse. Science 277:1515-1518.

Overstreet LS, Kinney GA, Liu YB, Billups D, Slater NT (1999) Glutamate transporters contribute to the time course of synaptic transmission in cerebellar granule cells. J Neurosci 19: 9663-9673.

Parks TN (1981) Morphology of axosomatic endings in an avian cochlear nucleus: nucleus magnocellularis of the chicken. J Comp Neurol 203:425-440.

Patneau DK, Vyklicky Jr L, Mayer ML (1993) Hippocampal neurons exhibit cyclothiazide-sensitive rapidly desensitizing responses to kainate. J Neurosci 13:3496-3509.

Raman IM, Trussell LO (1992) The kinetics of the response to glutamate and kainate in neurons of the avian cochlear nucleus. Neuron 9:173-186.

Raman IM, Trussell LO (1995a) Concentration-jump analysis of voltage-dependent conductances activated by glutamate and kainate in neurons of the avian cochlear nucleus. Biophys J 69:1868-1879.

Raman IM, Trussell LO (1995b) The mechanism of alpha-amino-3hydroxy-5-methyl-4-isoxazolepropionate receptor desensitization after removal of glutamate. Biophys J 68:137-146.

Rossi DJ, Slater NT (1993) The developmental onset of NMDA receptor-channel activity during neuronal migration. Neuropharmacology 32:1239-1248.

Rothstein JD, Dykes-Hoberg M, Pardo CA, Bristol LA, Jin L, Kuncl RW, Kanai Y, Hediger MA, Wang Y, Schielke JP, Welty DF (1996) Knockout of glutamate transporters reveals a major role for astroglial transport in excitotoxicity and clearance of glutamate. Neuron 16:675-686.

Scanziani M, Salin PA, Vogt KE, Malenka RC, Nicoll RA (1997) Usedependent increases in glutamate concentration activate presynaptic metabotropic glutamate receptors. Nature 385:630-634.

Tanaka K, Watase K, Manabe T, Yamada K, Watanabe M, Takahashi K, Iwama H, Nishikawa T, Ichihara N, Kikuchi T, Okuyama S, Kawashima N, Hori S, Takimoto M, Wada K (1997) Epilepsy and exacerbation of brain injury in mice lacking the glutamate transporter GLT-1. Science.276:1699-1702.

Tong G, Jahr CE (1994) Block of glutamate transporters potentiates postsynaptic excitation. Neuron 13:1195-1203.

Tong G, Shepherd D, Jahr CE (1995) Synaptic desensitization of NMDA receptors by calcineurin. Science 267:1510-1512.

Trussell L (1998) Control of time course of glutamatergic synaptic currents. Prog Brain Res 116:59-69.

Trussell LO, Zhang S, Raman IM (1993) Desensitization of AMPA receptors upon multiquantal neurotransmitter release. Neuron 10:1185-1196.

Tureček R, Trussell LO (1998) Control of synaptic depression by glutamate transporters. Soc Neurosci Abstr 24:624.

von Gersdorff H, Schneggenburger R, Weis S, Neher E (1997) Presynaptic depression at a calyx synapse: the small contribution of metabotropic glutamate receptors. J Neurosci 17:8137-8146.

Wadiche JI, Amara SG, Kavanaugh MP (1995) Ion fluxes associated with excitatory amino acid transport. Neuron 15:721-728.

Warchol ME, Dallos P (1990) Neural coding in the chick cochlear nucleus. J Comp Physiol [A] 166:721-734.

Yamada KA, Tang CM (1993) Benzothiadiazides inhibit rapid glutamate receptor desensitization and enhance glutamatergic synaptic currents. J Neurosci 13:3904-3915.

Zhang S, Trussell LO (1994a) A characterization of excitatory postsynaptic potentials in the avian nucleus magnocellularis. J Neurophysiol 72:705-718

Zhang S, Trussell LO (1994b) Voltage clamp analysis of excitatory synaptic transmission in the avian nucleus magnocellularis. J Physiol (Lond) 480:123-136. 